\title{
Comparative effect of immature neuronal or glial cell transplantation on motor functional recovery following experimental traumatic brain injury in rats
}

\author{
FU-SHI QUAN, JIAN CHEN, YUAN ZHONG and WEN-ZHI REN \\ Laboratory Animal Center, College of Animal Sciences, Jilin University, Changchun, Jilin 130062, P.R. China
}

Received March 12, 2015; Accepted April 11, 2016

DOI: $10.3892 /$ etm.2016.3527

\begin{abstract}
The present study evaluated the comparative effect of stereotaxically transplanted immature neuronal or glial cells in brain on motor functional recovery and cytokine expression after cold-induced traumatic brain injury (TBI) in adult rats. A total of 60 rats were divided into four groups ( $\mathrm{n}=15 /$ group): Sham group; TBI only group; TBI plus neuronal cells-transplanted group (NC-G); and TBI plus glial cells-transplanted group (GC-G). Cortical lesions were induced by a touching metal stamp, frozen with liquid nitrogen, to the dura mater over the motor cortex of adult rats. Neuronal and glial cells were isolated from rat embryonic and newborn cortices, respectively, and cultured in culture flasks. Rats received neurons or glia grafts $\left(\sim 1 \times 10^{6}\right.$ cells $) 5$ days after TBI was induced. Motor functional evaluation was performed with the rotarod test prior to and following glial and neural cell grafts. Five rats from each group were sacrificed at 2, 4 and 6 weeks post-cell transplantation. Immunofluorescence staining was performed on brain section to identify the transplanted neuronal or glial cells using neural and astrocytic markers. The expression levels of cytokines, including transforming growth factor- $\beta$, glial cell-derived neurotrophic factor and vascular endothelial growth factor, which have key roles in the proliferation, differentiation and survival of neural cells, were analyzed by immunohistochemistry and western blotting. A localized cortical lesion was evoked in all injured rats, resulting in significant motor deficits. Transplanted cells successfully migrated and survived in the injured brain lesion, and the expression of neuronal and astrocyte markers were detected in the NC-G and GC-G groups, respectively. Rats in the NC-G and GC-G cell-transplanted groups exhibited significant motor functional recovery and reduced histopathologic lesions, as compared with the TBI-G
\end{abstract}

Correspondence to: Dr Wen-Zhi Ren, Laboratory Animal Center, College of Animal Sciences, Jilin University, 5333 Xi'an Road, Changchun, Jilin 130062, P.R. China

E-mail: renwenzhi_1@163.com

Key words: neuron, glia, transplantation, motor functional recovery, traumatic brain injury rats that did not receive neural cells $(\mathrm{P}<0.05$, respectively). Furthermore, GC-G treatment induced significantly improved motor functional recovery, as compared with the NC-G group $(\mathrm{P}<0.05)$. Increased cytokine expression levels were detected in the NC-G and GC-G groups, as compared with the TBI-G; however, no differences were found between the two groups. These data suggested that transplanted immature neural cells may promote the survival of neural cells in cortical lesion and motor functional recovery. Furthermore, transplanted glial cells may be used as an effective therapeutic tool for TBI patients with abnormalities in motor functional recovery and cytokine expression.

\section{Introduction}

Traumatic brain injury (TBI) remains one of the most serious types of neurologic degeneration in humans and the deleterious effects occur during distinct primary and secondary periods (1). Primary injury, which is induced by initial mechanical force trauma, results in the tearing and shrinkage of neural and vascular tissue. Following primary injury, the secondary periods are induced by ischemia, edema, ionic imbalances and energy metabolic changes $(1,2)$ TBI results in motor and cognitive deficits that may persist for a prolonged period of time after the traumatic event (2).

Potential therapeutic strategies have been investigated for the treatment of patients following TBI (3). It has previously been established that the multifaceted derangements of cell function and corresponding cell death after TBI were the most important events that resulted in cognitive and emotional disabilities (3). Previous research has focused on the clinical treatment to restrain these derangements and improve cognitive and motor recovery (4). Additionally, an increasing number of studies have investigated the potential therapeutic applications of lactate $(4)$, progesterone $(5,6)$, ginseng extract $(7)$ and resveratrol (8). Although various approaches have been established to protect neurons and improve the cognitive and motor recovery (7), the adverse effects and complicated purification techniques have restricted the clinic application of these techniques to date (8).

These approaches have only been demonstrated to improve the neurons that remain following TBI. Therefore, successful restoration of the injured brain must be accompanied by the regeneration or transplantation of neural cells. Previous studies 
have suggested that genetically engineered cells, including brain tissue, embryonic stem cells, adult stem cells and neural stem cells, are capable of integrating and differentiating to restore brain function (9-12). More recently, neural stem cells have been investigated and the results demonstrated that these cells survived and grafted into the host architecture following transplantation into newborn or adult mice or rat brains, and were capable of differentiating into neurons and glia lineages, replacing lost neural cells, improving clinical outcomes after experimental TBI and providing a platform for gene-based therapies (13-19).

Conversely, another previous study found that stem cells differentiated into neural cells and increased cytokine levels in host brains (20). These contrasting findings question the ability of stem cells to replace the damaged brain architecture and suggest that the recovery of function following stem cell transplantation in TBI may be associated with the cytokine production abilities of neural cells, which differentiate from transplanted stem cells.

Although various cells, including embryonic stem cells, adult stem cells and neural stem cells, have been demonstrated to improve functional recovery and protect remnant neurons in various animal models (20-24), the precise mechanism remains unknown. Notably, when injected with embryonic stem cells during a previous study, some rats developed teratoma at the implantation site (21), which fuelled the heated ethical debates over the use of embryonic stem cells. Adult stem cells can effectively avoid these problems, however the multiplication and conservation of stem cells remains very difficult (25). Furthermore, the source of neural stem cells limits its use as only the brains of fetuses aged $>12-14$ weeks old contain neural stem cells (26) Alternatively, cultured immature neural cells have higher security, wide source and easy propagation in vitro and have no problem of immunity and ethic (23). Nevertheless, the comparative effects of immature neurons and glia on motor functional recovery after TBI following direct administration into the brain have rarely been reported.

Therefore, to explore the therapeutic potential of immature neural cell transplantation for brain repair, the present study was undertaken to examine the comparative effect of stereotaxically transplanted neurons or glia on motor functional recovery in a rat model of TBI. Firstly, whether neurons or glia migrate into the focal injury area via brain tissue to protect the remnant neural cells and replace the lost cells was assessed. Secondly, cytokine levels were analyzed following cell transplantation to examine whether transplanted neural cells were capable of creating an environment that was conducive to functional recovery via cytokines production. Thirdly, the possible effective differences in motor functional recovery between neurons or glia transplantation were investigated.

\section{Materials and methods}

Animals and experimental groups. A total of 60 male Sprague-Dawley rats, weighing 220 g and aged 7 weeks \pm 2 days, were purchased from the Experimental Animal Center of the College of Animal Sciences at Jilin University (Changchun, China) and were used in the present study. Rats were maintained at $22^{\circ} \mathrm{C}$ (humidity, 60\%) with a 12-h light/dark cycle and ad libitum access to food and tap water. All experimental procedures were approved by the Institutional Animal Care and Use Committee of Jilin University.

Rats were divided into four groups (n=15/group): i) Sham (CON); ii) TBI plus neuronal cells-transplanted group (NC-G), rats were transplanted neuronal cells 5 days after TBI; iii) TBI plus glial cells-transplanted group (GC-G), rats were transplanted glial cells 5 days after TBI; iv) TBI only group (TBI-G), rats received TBI only. Five rats from each group were sacrificed at 2, 4 and 6 weeks after the graft via an overdose of sodium pentobarbital $(30 \mathrm{mg} / \mathrm{kg}$; Abbott Laboratories, Chicago, IL, USA).

Isolation and neuronal and glial cell culture. Cortical neuron cultures were harvested from the brains of 16-day-old rat embryos according to a modified procedure outlined by Freshney in 1987 (23). Briefly, cerebral hemispheres were isolated and placed into $\mathrm{Ca}^{2+} / \mathrm{Mg}^{2+}$-free Hank's balanced salt solution (Gibco; Thermo Fisher Scientific, Inc., Waltham, MA, USA). Brain tissue was dissociated in $0.025 \%$ trypsin for $10 \mathrm{~min}$ at $37^{\circ} \mathrm{C}$ and the proteolytic reaction was subsequently terminated by adding the same quantity of Dulbecco's modified Eagle medium (DMEM) and fetal bovine serum (FBS; both Gibco; Thermo Fisher Scientific, Inc.). Following centrifugation at $157 \mathrm{x} \mathrm{g}$ for $15 \mathrm{~min}$ at $4^{\circ} \mathrm{C}$, the pellet containing the dissociated neuronal cells was resuspended in neurobasal media containing 400X L-glutamine (200 Mm), 50X B27, $100 \mathrm{X}$ penicillin and streptomycin antibiotics (all Gibco; Thermo Fisher Scientific, Inc.) and 200X glutamate (5 Mm; Sigma-Aldrich RBI, Natick, MA, USA). The concentration of the cells was adjusted to $2 \times 10^{6}$ cells $/ \mathrm{ml}$ and the viability of the cells was $85 \%$, as determined by the trypan blue dye exclusion method (24). Cells were seeded onto a poly-D-lysine $(50 \mu \mathrm{g} / \mathrm{ml}$; Sigma-Aldrich, St. Louis, MO USA) and lamine $(1 \mu \mathrm{g} / \mathrm{ml}$; Gibco; Thermo Fisher Scientific, Inc.)-coated 6-well plastic plate at a concentration of $1 \times 10^{6}$ cells/well and maintained at $37^{\circ} \mathrm{C}$ in an atmosphere containing $95 \%$ air and $5 \% \mathrm{CO}_{2}$.

Mixed glial cell cultures were prepared from dissociated cerebral cortices of newborn rats. Dissociation of the cerebral hemispheres and cell culture were performed as described above for the cortical neuronal cells, although the components of the culture media were altered to DMEM supplemented with $10 \%$ FBS and 1\% antibiotic solution (100X; Gibco; Thermo Fisher Scientific, Inc.).

Preparation of cells for transplantation and microinjection. Cultured neural cells were labeled with DiI fluorescent dye (1,1-dilinoleyl-3,3,3',3'-tetramethylindocarbocyanine, perchlorate) prior to injection to ensure the cells appeared red. A total of 45 rats were randomly selected, anesthetized with $8 \%$ chloral hydrate $(400 \mathrm{mg} / \mathrm{kg})$ by intraperitoneal injection and placed in a stereotaxic frame. Microinjection coordinates (1 $\mathrm{mm}$ posterior, $1.5 \mathrm{~mm}$ right lateral, $2 \mathrm{~mm}$ ventral to the bregma) were selected according to a rat brain atlas and microinjection was performed using a $20 \mu$ l Hamilton syringe with a 22-gauge needle. Five days after TBI, rats received a microinjection of $10 \mu \mathrm{l}$ cell suspension $\left(\sim 1 \times 10^{6}\right.$ cells $)$. The cell suspension was separated into 5 parts and injected slowly over 25 min with 5 min intervals for each $2 \mu 1$ cell suspension. 
Surgical procedure for establishment of TBI models. In the present study, a well-characterized traumatic injury model was used, as previously described (27). This injury model was selected as it is readily reproducible and allows for the comparison of affected (ipsi-) and non-affected (contralateral) hemispheres. Following intraperitoneal injection with $10 \%$ chloral hydrate $(3.5 \mathrm{ml} / \mathrm{kg})$ anesthesia, the head was fixed in a stereotaxic frame. Subsequently, the scalp was longitudinally incised and the indiction was made on the right motor cortex (4 $\mathrm{mm}$ anterior from the lambdoid suture; $2 \mathrm{~mm}$ lateral from the midline). A probe (diameter, 4-mm) was pre-cooled with liquid nitrogen and used to touch the surface of the skull for 20 sec. Subsequently, the skin was sutured using 3.0 nylon in a running whipstitch and the rats were observed until they awoke.

Assessment of motor function. The modified rotarod test is widely used to evaluate the motor coordination of rodents, and is especially sensitive in detecting cerebellar dysfunction (26). All the rats underwent conditioning of the rotarod test for three trials a day for 5 days prior to TBI. Motor behavior was analyzed daily for three trials on days 1, 5, 7, 14, 28 and 42 following TBI by a blinded observer using rotarod apparatus (Med Associates, Inc, St. Albans, VT, USA). Rats were placed on a rotating rod which was set to slowly accelerate from 4-40 rpm over $5 \mathrm{~min}$. The rotarod test requires the rat to walk and maintain balance as the revolving rod accelerates. The trial was terminated when the rat fell off the apparatus and tripped a plate which recorded the time.

Tissue preparation. At 2, 4 and 6 weeks following neural cell injection, rats were anesthetized with intraperitoneal injection of $10 \%$ chloral hydrate $(3.5 \mathrm{ml} / \mathrm{kg})$ and intracardially perfused with $150 \mathrm{ml}$ normal saline and $300 \mathrm{ml}$ ice-cold $4 \%$ paraformaldehyde in phosphate-buffered saline (PBS; $\mathrm{pH}$ 7.4). The brains of the rats were removed and post-fixed in the same fixative overnight at $4^{\circ} \mathrm{C}$. Brain images were captured using a digital camera. Necrotic areas were measured using morphometry software (Axiovision 3.0.6 SP4; Carl Zeiss AG, Oberkochen, Germany). For light microscopy studies, tissues were embedded in paraffin blocks.

Immunofluorescence. For immunofluorescence imaging, $5 \mu \mathrm{m}$-thick paraffin-embedded brain sections were cut, deparaffinized and rinsed in PBS. Sections were incubated in PBS supplemented with $3 \%$ bovine serum albumin (BSA), $10 \%$ normal calf serum and $1 \%$ Triton $\mathrm{X}-100$ for $1 \mathrm{~h}$ at room temperature to block nonspecific binding. Subsequently, the sections were incubated overnight at $4^{\circ} \mathrm{C}$ with mouse anti-neuronal nuclei (NeuN; 1:500; ab18956; Abcam, Cambridge, UK) and rabbit anti-glial fibrillary acidic protein (GFAP; 1:1,000; MA191029; Chemicon International, Inc., Temecula, CA, USA) monoclonal antibodies in PBS containing 1\% Triton X-100. Following washing in PBS for $30 \mathrm{~min}$ (6 times for $5 \mathrm{~min}$ ), the sections were incubated with fluorescein isothiocyanate-conjugated, affinity-purified anti-mouse IgG and anti-rabbit IgG (both 1:200; both Jackson Immuno-Research Laboratories, West Grove, PA, USA) for $2 \mathrm{~h}$ at room temperature. Following washing in PBS for $30 \mathrm{~min}$, the sections were mounted with mounting medium and examined under a fluorescence microscope (Olympus BX51; Olympus Corporation, Tokyo, Japan).
Immunohistochemistry. Sections $(5 \mu \mathrm{m})$ were cut, mounted on positively-charged slides, air-dried in an incubator at $40^{\circ} \mathrm{C}$ overnight and deparaffinized in xylene. Following rehydration with a graded alcohol series, the slides were incubated with $1 \%$ hydrogen peroxide diluted in methanol for $15 \mathrm{~min}$ to block endogenous peroxidase activity, and were subsequently rehydrated in distilled water and PBS. Following this, the slides were incubated with a blocking solution (PBS supplemented with $3 \%$ BSA and $10 \%$ normal calf serum) for $60 \mathrm{~min}$ at room temperature. This solution was removed from the slides using filter paper and the samples were incubated with the respective primary antibodies overnight at $4^{\circ} \mathrm{C}$. The following primary antibodies were used: Mouse anti-glial cell-derived neurotrophic factor (GDNF; ab18956), rabbit anti-transforming growth factor (TGF)- $\beta$ (both 1:500; ab66043) and mouse anti-vascular endothelial growth factor (VEGF; 1:400; ab46154; all Abcam). Following removal of the unbound antibodies via several rinses with PBS followed by PBS containing $0.1 \%$ Triton $\mathrm{X}-100$, the respective antibodies were detected using the avidin-biotin-peroxidase complex method (orb90540) and visualized using 3,3'-diaminobenzidine. Slides were lightly counterstained with hematoxylin.

Double-labeled sections were observed with an Olympus BH2 light microscope or an Olympus FV-1000 confocal laser-scanning microscope. The five darkest points of the images obtained by light microscopy were analyzed via densitometry using Multi Gauge 3.0 software (Fujifilm Life Science, Minato, Tokyo, Japan).

Western blotting. The cortex of each rat at the injury site was harvested on ice. Following washing with $0.9 \%$ sodium chloride, the clean tissue was preserved in liquid nitrogen until use. A protein preparation kit was used to exact the protein, and the concentration was measured by the Bradford method. Protein samples $(20 \mu \mathrm{g})$ from cortex of each rat at injury site were separated by $12 \%$ gel electrophoresis and transferred on to polyvinylidene difluoride membranes (EMD Millipore, Billerica, MA, USA). Membranes were blocked in Tris-buffered saline with Tween 20 (TBS-T; pH 7.4) supplemented with $3 \%$ skimmed milk, and subsequently incubated overnight at $4^{\circ} \mathrm{C}$ with anti-TGF- $\beta$, anti-GDNF and anti-VEGF primary antibodies (1:500). Following washing, the membranes were incubated with the following secondary antibodies: Anti-mouse IgG (CABT-ZC1010) for GDNF and VEGF and anti-rabbit IgG (CABT-ZC1022) for TGF- $\beta$ (1:2,000; Jackson Immuno-Research Laboratories) for $2 \mathrm{~h}$ at room temperature. All antibodies were diluted in TBS-T supplemented with $3 \%$ skimmed milk. The membranes were developed using enhanced chemiluminescent reagent and subjected to autoluminography for $2 \mathrm{~min}$. Membranes were exposed on X-ray film (Eastman Kodak Company, Rochester, NY, USA). Blots were subsequently striped and re-blotted with mouse anti- $\beta$-actin primary antibody $(1: 5,000$; ab54724; Abcam), followed by incubation with anti-mouse IgG secondary antibody (1:2,000; PA128555; Thermo Fisher Scientific, Inc.).

Statistical analysis. Data were analyzed using SAS 8.1 (SAS Institute Inc., Cary, NC, USA) with analysis of variance. $\mathrm{P}<0.05$ was considered to indicate a statistically significant 
difference. Data are presented as the mean \pm standard deviation.

\section{Results}

Cell culture. The isolated cells were successfully induced to differentiate into immature neurons and glia, respectively (Figs. 1A and B). Neurons and glia were stained with NeuN neuronal marker and GFAP astrocyte marker, respectively (Figs. 1C and D).

Characterization of the brain cortex following TBI and post-transplantation. Establishment of the rat model of TBI resulted in a wedge-like cold brain lesion which affected the motor cortex. The dorsal view of the brain 6 weeks post-TBI demonstrated that there was a marked difference in the injury area between the TBI-G and the NC-G and GC-G (Figs. 2A-C). The NC-G and GC-G exhibited decreased injury areas, as compared with the TBI only control group, TBI-G. Quantitative analysis of the lesion area 6 weeks post-TBI demonstrated that transplantation with neuronal and glial cells following TBI significantly reduced the injury area in the cerebral cortex $(\mathrm{P}<0.05$; Fig. 1D).

Body weight. As compared with the rats in NC-G and GC-G, the mean body weight of the rats in the TBI-G was lowest from the day of TBI administration to 6 weeks post-TBI, and a notable decrease was observed at 2 weeks post-TBI (Fig. 3A). The body weight of rats in the CON-G remained significantly higher than other groups across all the time points $(\mathrm{P}<0.05)$. The NC-G and GC-G demonstrated significantly higher body weight increases, as compared with the TBI-G at 2 weeks post-TBI $(\mathrm{P}<0.05)$. Rats in the GC-G exhibited significantly increased body weight at 4 and 6 weeks post-TBI, as compared with the NC-G.

Assessment of motor function outcome. No significant differences in mean rotarod scores were observed between the CON-G and the other groups prior to TBI (Fig. 3B). Following TBI, TBI-G, NC-G and GC-G demonstrated a significant decline in rotarod performance, as compared with their pre-TBI scores. Rotarod scores of rats in NC-G and GC-G were significantly higher than TBI-G at 2, 4 , 6 weeks post-cell transplantation $(\mathrm{P}<0.05)$. Furthermore, the $\mathrm{GC}-\mathrm{G}$ demonstrated a reduced decline in rotarod scores, as compared with NC-G and TBI-G, suggesting glial cell transplantation promoted the recovery of motor function. No significant changes in rotarod performance were detected for rats in the $\mathrm{CON}-\mathrm{G}$ at any time.

Migration of transplanted cells. Migration ability of transplanted-neurons or transplanted-glia were observed vai the longitudinal view of the brain at 2, 4 and 6 weeks post-cell transplantation. As shown in Fig. 4, transplanted cells migrated via the corpus callosum from the injection site to the TBI lesion at 2 weeks. The number of transplanted-neurons and transplanted-glia at injection site decreased, whereas the number of these cells increased with time at the TBI site. The number changes of neurons and gila with labeling Dil in cortex and corpus callosum were similar.
Histological characterization of the TBI lesion. DiI pre-labeled neuronal or glia were observed at the injection site and surrounding areas of TBI injury 2, 4 and 6 weeks post-transplantation. In NC-G, DiI-positive cells exhibited immunoreactivity for the NeuN neuronal marker and substantial co-expression, as shown in Fig. 5; however these cells did not exhibit immunoreactivity for GFAP. In GC-G, the pre-labeled glia were immunoreactive for the GFAP astrocytic marker but did not exhibit immunoreactivity for NeuN. These results demonstrated that the transplanted neurons and glia, although small in population, successfully migrated from the transplant site to the TBI lesion and differentiated into neural cells in vivo following TBI.

Immunohistochemistry. GDNF expression levels decreased in a time-dependent manner; whereas TGF- $\beta$ and VEGF expression levels increased with time (Fig. 6). Quantitative analysis demonstrated that TBI-G, NC-G and GC-G exhibited variable TGF- $\beta(\mathrm{P}<0.05)$, GDNF $(\mathrm{P}>0.05)$ and VEGF $(\mathrm{P}>0.05)$ expression levels at 2, 4 and 6 weeks post-transplantation. NC-G and GC-G exhibited significantly increased secretion of the three cytokines, as compared with TBI-G at the same time points. Moreover, GC-G treatment significantly increased the expression of TGF- $\beta$, GDNF and VEGF, as compared with NC-G.

Western blot analysis. The expression levels of TGF- $\beta$, VEGF and GDNF in each group, as detected by western blotting, are shown in Fig. 7. The expression levels of CON-G. TGF- $\beta$, VEGF and GDNF were increased in NC-G and GC-G, as compared with the CON-G. TGF- $\beta$, VEGF and GDNF expression levels were increased in $\mathrm{GC}-\mathrm{G}$, as compared with $\mathrm{NC}-\mathrm{G}$.

Confocal microscopy. Confocal microscopy demonstrated the expression of TGF- $\beta$, VEGF and GDNF in neural cells at the injury site (data not shown). TGF- $\beta$, VEGF and GDNF expression was observed in transplanted-neurons and transplanted-glia. These results indicated that transplanted-neurons and glia may secrete TGF- $\beta$, VEGF and GDNF.

\section{Discussion}

The results of the present study demonstrated, when transplanted after the induction of TBI in rats, immature neurons or glia migrated from the injection site to the TBI lesion and significantly improved motor functional recovery, as assessed by rotarod test at 2, 4 and 6 weeks. In NC-G and GC-G, respective neuronal and glial cell transplantation significantly reduced the injury area in the ipsilateral cerebral cortex and significantly increased the expression levels of TGF- $\beta$, GDNF, and VEGF in the surrounding TBI lesion, as compared with the TBI-G. Moreover, glial cell transplantation markedly reduced the initial motor impairments induced by TBI, as compared with neuronal cell transplantation. Following cell transplantation, the rotarod scores of NC-G and GC-G increased, as compared with TBI-G. Therefore, the GC-G group resisted the decline of rotarod scores and promoted the recovery of motor function, compared with NC-G and TBI-G.

Previous studies have investigated functional recovery following stem cell transplantation in models of TBI. Undifferentiated stem cells, including bone marrow (28), 
A

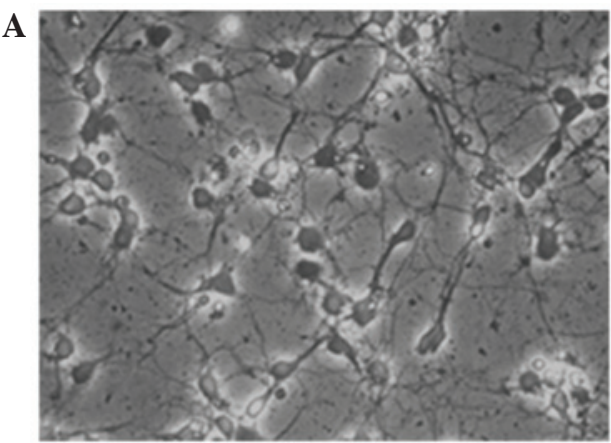

C

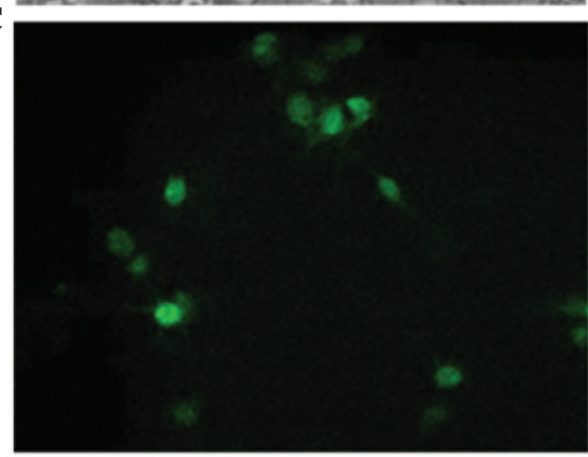

B

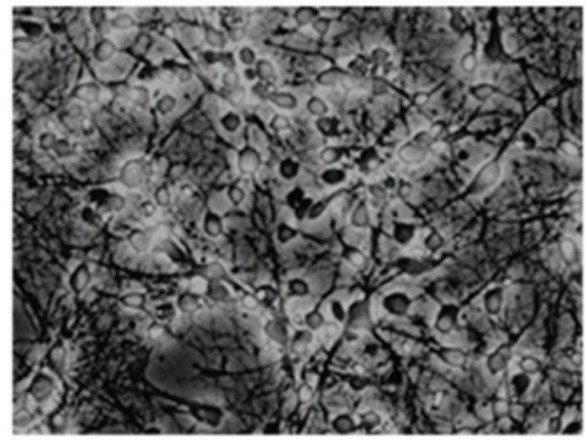

$\mathbf{D}$

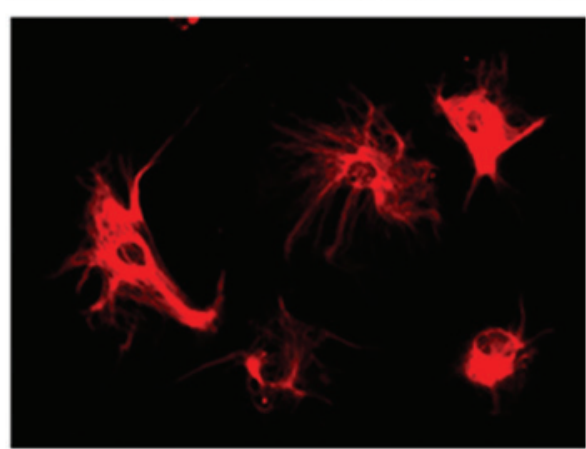

Figure 1. Newly isolated cells in the culture dish differentiate into both (A) immature neurons and (B) astrocytes. Confocal microscopic images demonstrated immature cells stained with the (C) NeuN neuronal marker (green) and the (D) glial fibrillary acidic protein astrocytic marker (red) at 5 days following culture. Magnification, $\mathrm{x} 400$.
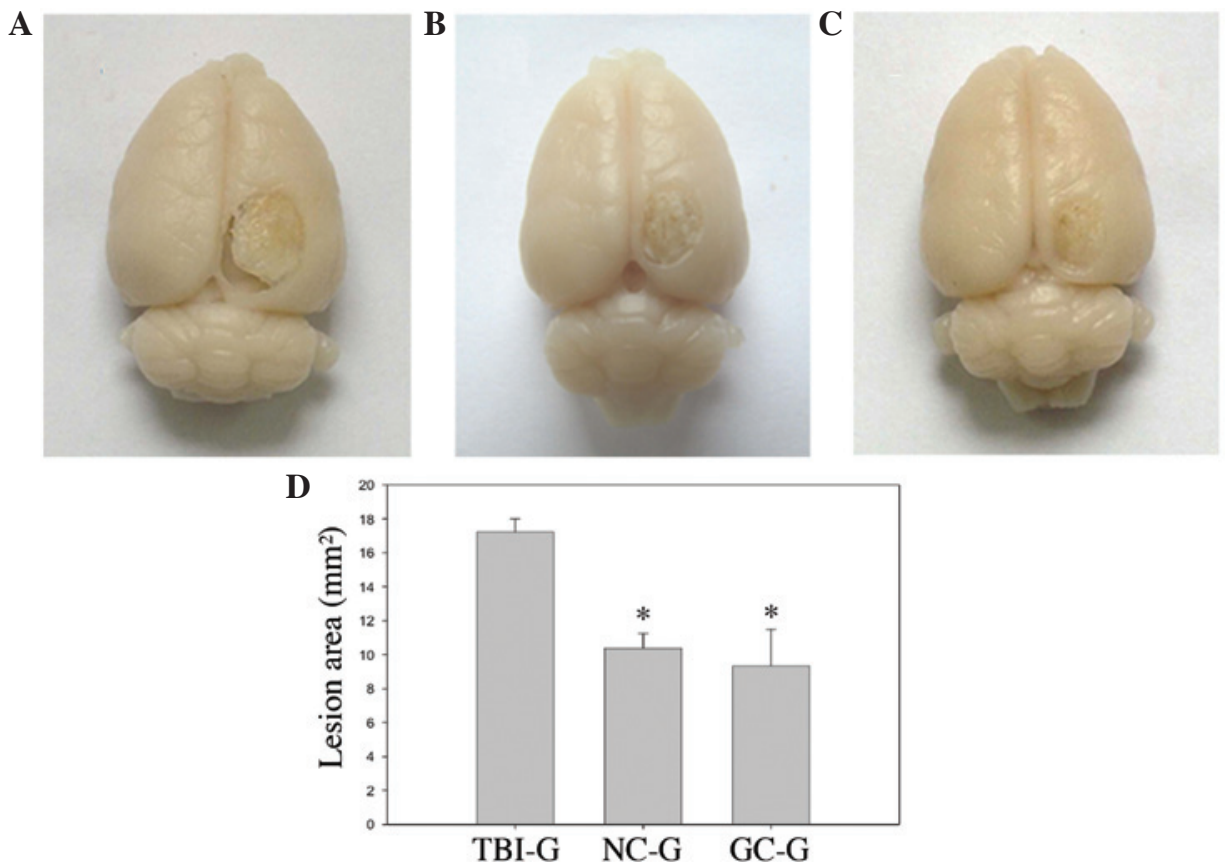

Figure 2. Effects of neural cell transplantation on a cold-induced brain lesion at 6 weeks post-cell injection in the (A) TBI, (B) NC-G and (C) GC-G groups (D) Quantitative analysis of the areas of the respective brain lesions demonstrated that the rats injected with (B) neuron or (C) glia cell transplants exhibited decreased lesion areas, as compared with (A) the sham TBI control. Data are expressed as the mean \pm standard error of the mean. ${ }^{*} \mathrm{P}<0.05$, as compared with the TBI-G control ( $\mathrm{n}=5$ /group). TBI, traumatic cold brain injury; NC-G, TBI plus neuronal cells-transplanted group; GC-G, TBI plus glial cells-transplanted group; TBI-G, TBI only group.

embryonic (29) and neural (30) stem cells, have the ability to differentiate into neurons and glial cells to replace lost neurons, improve outcomes after experimental TBI and provide a platform for gene-based therapies (14-17,31,32). In previous studies, a positive correlation was detected between the survival of transplanted cell and functional recovery $(33,34)$. However, brain trauma leads to the production of free radicals, excitotoxicity, calcium overloading, cytokine secretion, and growth-factor activation or withdrawal $(35,36)$, which are not only harmful to brain cells but also to transplanted cells (37). Furthermore, teratoma development $(21,34)$, ethical debates, multiplication and conservation difficulty (25) have limited its use. 
In the present study, first, the survival and migration ability of transplanted immature neurons or glia were evaluated, which avoided the problem of undifferentiated stem cells, in a rat model of TBI. On day 5 after TBI was established, immature neuronal and glial cells were injected into the rats far from the injury site to enhance the survival of transplanted cells. DiI, which is a lipophilic membrane stain that diffuses laterally to stain the entire cells, was used as a marker for transplanted cells. It is possible that non-transplanted cells, which graft and migrate into the brain, may pick up DiI, and stain positively. Brain sections from rats in NC-G and GC-G were double-stained with NeuN or GFAP antibodies and DiI. Transplanted cells, which were positive for NeuN or GFAP and DiI, were observed in the cerebral cortex and corpus callosum of the injection site, which is the space from the transplanted site to the injured site. Previous studies have shown that ipsilateral and contralateral transplantation of neural stem cells or human mesenchymal stem cells resulted in migration from the injection site to the injury site and significantly improved motor functions (38). However, to the best of our knowledge, this is the first report of long distance migration of neural cells. The present results indicated that transplanted neural cells are also capable of migrating to an injured site via subcortical structures in response to brain injury. Furthermore, cell counting of brain sections from four different sites (injection site, $1 / 3$ and $2 / 3$ distance between injection and injury site, and injury site) demonstrated a decrease in the number of cells at the injection site and an increase at injury site at 2, 4 and 6 weeks post-transplantation. These results also demonstrated a temporal migration of transplanted cells from the injection site to the injury site as the assemble of transplanted cells were observed at a $1 / 3$ distance from the injection site to the injury site at 4 weeks post-TBI and at a $2 / 3$ distance at 6 weeks in the corpus callosum. The precise mechanism for the present finding that transplanted-neurons and glia are capable of migrating to injured lesions following TBI is yet to be fully elucidated.

To investigate whether changes at the cytokine level contribute to the recovery of motor function following TBI, the effects of transplantation with neurons or glia on the expression of cytokines were assessed in rat models of TBI. The results of the present study demonstrated that transplantation of neurons or glia induced increased cytokine expression at the injury site. It has previously been demonstrated that cytokines are associated with functional recovery following brain injury (33). GDNF has an important role in the differentiation of neurons during normal development and the survival and recovery of various populations of mature neurons (33). GDNF, which is a potent and relatively specific neurotrophic factor, has been demonstrated to have a protective effect on various injuries of central and peripheral nervous systems in vitro and in vivo (18). Wei et al demonstrated that the expression of GDNF mRNA and protein was first increased as early as $2 \mathrm{~h}$ after ischemia-reperfusion in peri-infarct cerebral cortex and striatum, followed by a decline and subsequent second increase at $72 \mathrm{~h}$ (39). Miyazaki et al (40) have previously shown that transient forebrain ischemia induced GDNF mRNA expression in the hippocampus from $3 \mathrm{~h}$ to 3 days after the ischemic episode, with peak expression detected at $6 \mathrm{~h}$.
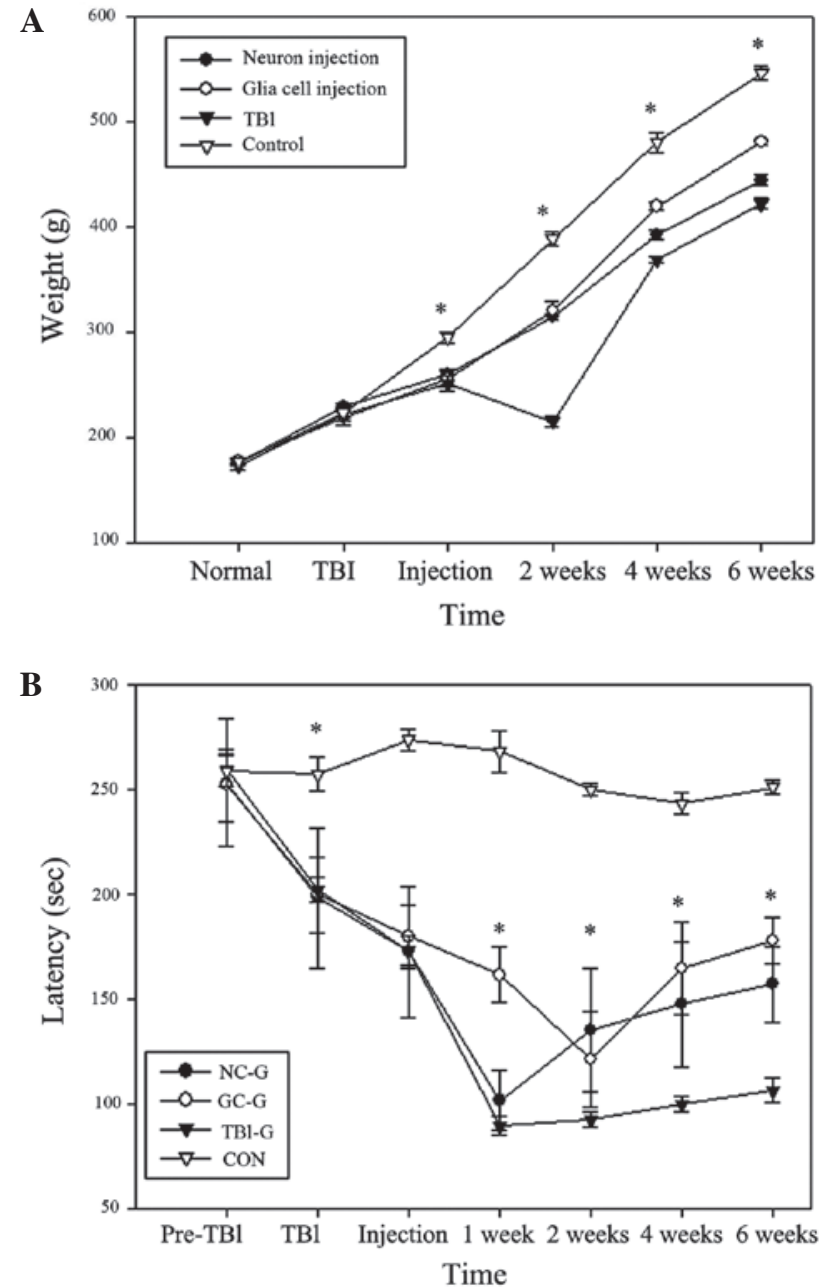

Figure 3. Effects of transplantation with neurons or glia cells on (A) body weight and (B) motor function recovery with rota rod test a rat model of TBI rats. The NC-G and GC-G exhibited significant improved motor function recovery and body weight as compared with the TBI-G ( $\mathrm{P}<0.05 ; \mathrm{n}=5 /$ group). Data are presented as the mean \pm standard deviation. TBI, traumatic cold brain injury; NC-G, TBI plus neuronal cells-transplanted group; GC-G, TBI plus glial cells-transplanted group; TBI-G, TBI only group; CON, control.

TGF- $\beta$ is a multifunctional peptide that controls proliferation, differentiation, and other functions in numerous cell types (41). TGF- $\beta$ has been demonstrated to be highly upregulated in the central nervous system following ischemia-induced brain damage (41). In vitro, TGF- $\beta$ protects neurons against excitotoxicity by inhibiting t-PA-potentiated NMDA-induced neuronal death through a mechanism involving the upregulation of plasminogen activator inhibitor type-1 in astrocytes $(41,42)$. In addition, TGF- $\beta$ has been characterized as an antiapoptotic factor in a model of staurosporine-induced neuronal death through a mechanism involving the activation of extracellular signal-regulated kinase (Erk) $1 / 2$ and a concomitant increase in the phosphorylation of the antiapoptotic protein B cell lymphoma-2-associated death promoter (42).

VEGF exerts neurotrophic effects which manifest as increased axonal outgrowth and improved cell survival in neuronal cultures $(42,43)$. VEGF also protects neurons from hypoxia (44) and glutamate toxicity (45), which may explain its ability to reduce injury and improve clinical outcomes after experimental stroke (46-48). Conversely, defective VEGF 

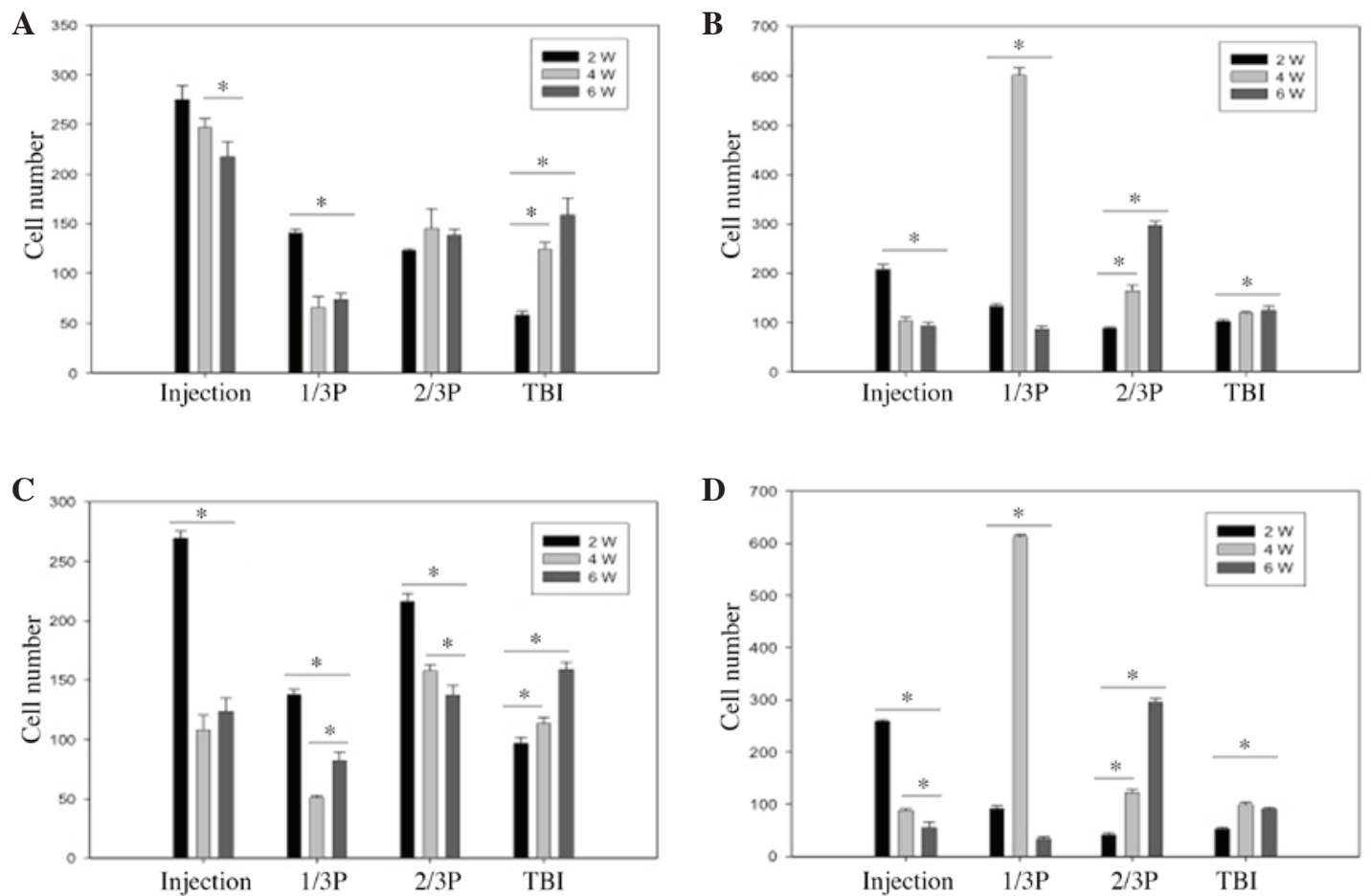

Figure 4. Number of transplanted neurons that survived up to 2, 4 and 6 weeks in different transverse planes of the (A) cerebral cortex and (B) corpus callosum and the number of transplanted glial cells that survived 2, 4 and 6 weeks in different transverse planes of the (C) cerebral cortex and (D) corpus callosum. Data are expressed as the mean \pm standard error of the mean. ${ }^{*} \mathrm{P}<0.05$ ( $\mathrm{n}=5 /$ group). $\mathrm{W}$, weeks; $1 / 3 \mathrm{P}$, the transverse plane at a $1 / 3$ interval from the injection site to the TBI site; $2 / 3 \mathrm{P}$, he transverse plane at a $2 / 3$ interval from the injection site to the TBI site; TBI, traumatic cold brain injury.

A

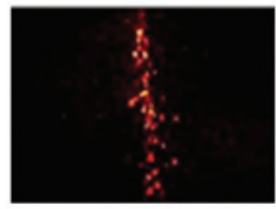

Cortex
B

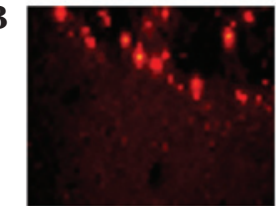

Cerebellum
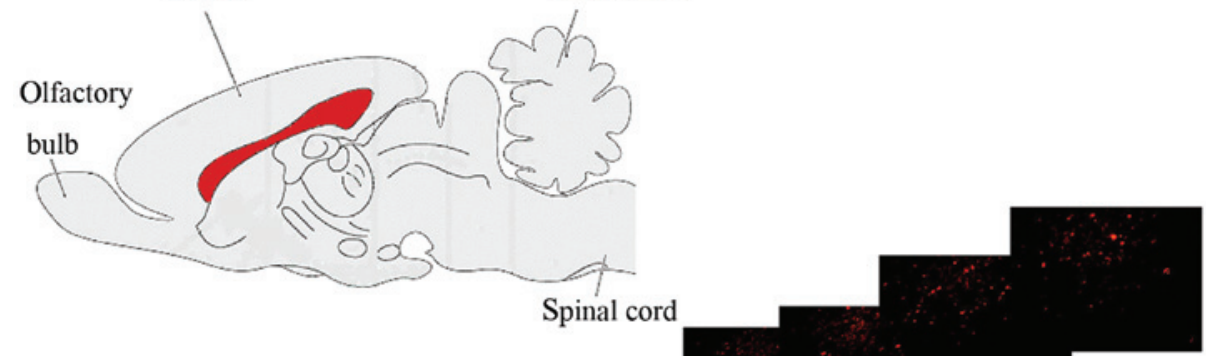

C

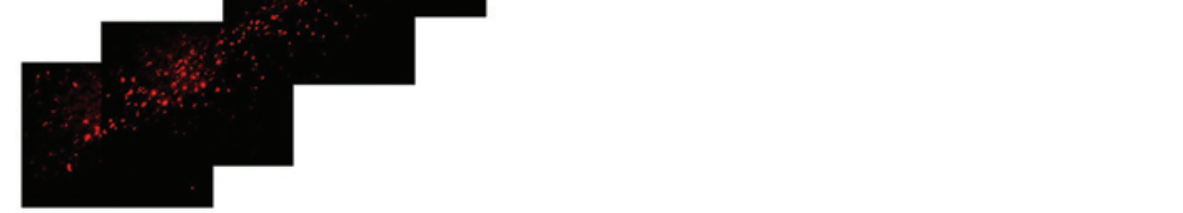

Figure 5. Brain median sagittal section showing the fluorescent dye DiI-lableling of transplanted neural cells via corpus callosum a successful migration from the (A) injection site to the (B) traumatic cold brain injury (TBI) site. (C) Confocal microscopic images of the TBI lesion at 2, 4, and 6 weeks following cell transplantation demonstrated double-labeling of injected cells with the neuronal nuclei (NeuN) neural marker and the glial fibrillary acidic protein (GFAP) astrocytic marker. DiI-positive cells (red) in the TBI lesion were co-stained with the NeuN neuronal or GFAP astrocytic (green) markers and merged as yellow. 

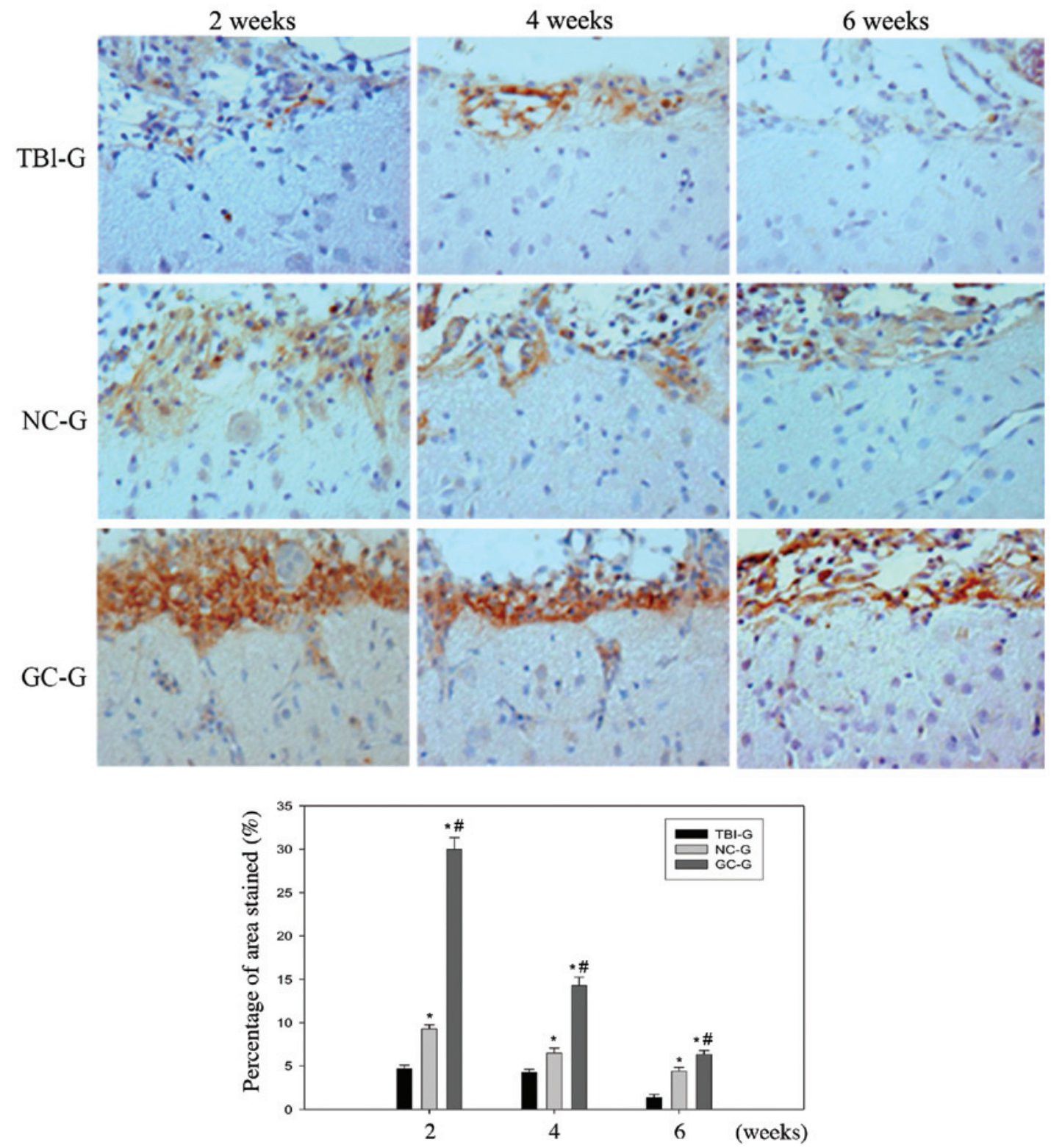

Figure 6. Effects of transplanted neurons or glia on the expression of TGF- $\beta$ in brain cold injury rats. Injured rats transplanted with neurons or glia exhibited significantly increased TGF- $\beta$ expression levels, as compared with the TBI-G rats. Compared to NC-G, the expression of TGF- $\beta$ in the TBI lesion was significantly higher in the GC-G. No significance difference in the expression of GDNF and VEGF was detected between injured rats transplanted with neurons or glia. Notably, the confocal images showed the expression of TGF- $\beta$, GDNF and VEGF in neural cells at the injury lesion site. "P<0.05 vs. the TBI-G; "P<0.05 vs. NC-G. TBI, traumatic brain injury; NC-G, TBI plus neuronal cells-transplanted group; GC-G, TBI plus glial cells-transplanted group; TBI-G, TBI only group..

signaling may contribute to motor neuronal disease (49-52). It has been demonstrated that VEGF stimulates neurogenesis, which is the production of novel neurons, in the adult songbird (53) and rodent brains (54). Therefore, the functional benefits induced by cell transplantation may be due to the neurotrophic factors produced by the transplanted cells (55). In the present study, the expression levels of GDNF, TGF- $\beta$, and VEGF at the TBI site were observed in NC-G, GC-G and TBI-G via immunohistochemistry and western blotting. Confocal microscopy demonstrated that the transplanted neurons and glia contained GDNF, TGF- $\beta$ and VEGF in their cytoplasm. Moreover the results of western blotting showed that GDNF, TGF- $\beta$ and VEGF expression was induced at higher levels in NC-G and GC-G, as compared with TBI-G. These results suggested that the transplanted cells induced the secretion of these cytokines and may create a salutary environment for

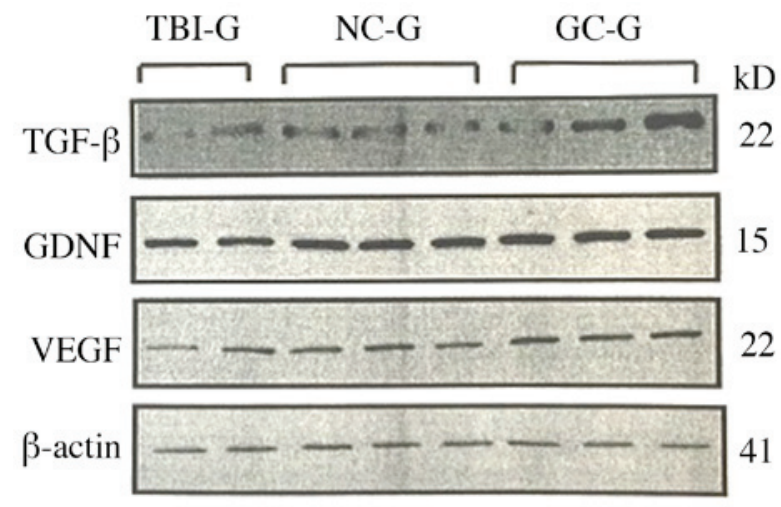

Figure 7. Western blot analysis was used to assess the expression levels of TGF- $\beta$, GDNF, VEGF and $\beta$-actin in the three groups. NC-G, TBI plus neuronal cells-transplanted group; GC-G, TBI plus glial cells-transplanted group; TBI-G, TBI only group; TGF. tumor growth factor. 
the survival of neural cells and the proliferation of microvessels. In addition, the expression levels of the three cytokines induced by transplantation with neuronal cells were lower than the levels observed following transplantation with glial cells. These findings are consistent with the results of the rotarod test and the survival and migration of transplanted cells in the ipsilateral cortex. Taken together, these results provide strong evidence that the transplanted-neurons and transplanted-glia have an important role in the control of cytokine expression levels and motor functional recovery following TBI.

In conclusion, the results of present study suggested that: i) Transplantation of cultured immature neurons and glia may be a potential treatment for motor functional recovery following TBI; ii) transplanted cells may have an important role in the activation of the GDNF, TGF- $\beta$, and VEGF expression; and iii) glial cell transplantation induces more beneficial effects on motor functional recovery following TBI, as compared with neuronal cell transplantation.

\section{Acknowledgements}

The present study was supported by the Youth Research Fund Project of Jilin Province (grant no. 2014-0520170JH) and the National Technology Support Project (grant no. 2015-BAI07B02).

\section{References}

1. Chirumamilla S, Sun D, Bullock MR and Colello RJ: Traumatic brain injury induced cell proliferation in the adult mammalian central nervous system. J Neurotrauma 19: 693-703, 2002.

2. Rice AC, Khaldi A, Harvey HB, Salman NJ, White F, Fillmore H and Bullock MR: Proliferation and neuronal differentiation of mitotically active cells following traumatic brain injury. Exp Neurol 183: 406-417, 2003.

3. Holloway R, Zhou Z, Harvey HB, Levasseur JE, Rice AC, Sun D, Hamm RJ and Bullock MR: Effect of lactate therapy upon cognitive deficits after traumatic brain injury in the rat. Acta Neurochir (Wien) 149: 919-927, 2007.

4. Rice AC, Zsoldos R, Chen T, Wilson MS, Alessandri B, Hamm RJ and Bullock MR: Lactate administration attenuates cognitive deficits following traumatic brain injury. Brain Res 928: 156-159, 2002.

5. Roof RL, Duvdevani R, Heyburn JW and Stein DG: Progesterone rapidly decreases brain edema: Treatment delayed up to $24 \mathrm{~h}$ is still effective. Exp Neurol 138: 246-251, 1996.

6. National institute on disability and rehabilitation research: Prevention and management of urinary tract infections among people with SCI: Consensus statement. NeuroRehabilitation 4: 222-236, 1994.

7. Ji YC, Kim YB, Park SW, Hwang SN, Min BK, Hong HJ, Kwon JT and Suk JS: Neuroprotective effect of ginseng total saponins in experimental traumatic brain injury. J Korean Med Sci 20: 291-296, 2005.

8. Gao D, Zhang X, Jiang X, Peng Y, Huang W, Cheng G and Song L: Resveratrol reduces the elevated level of MMP-9 induced by cerebral ischemia-reperfusion in mice. Life Sci 78: 2564-2570, 2006.

9. Kesslak JP, Brown L, Steichen C and Cotman CW: Adult and embryonic frontal cortex transplants after frontal cortex ablation enhance recovery on a reinforced alternation task. Exp Neurol 94 615-626, 1986

10. Muir JK, Raghupathi R, Saatman KE, Wilson CA, Lee VM, Trojanowski JQ, Philips MF and McIntosh TK: Terminally differentiated human neurons survive and integrate following transplantation into the traumatically injured rat brain. J Neurotrauma 16: 403-414, 1999.

11. Netto CA, Hodges H, Sinden JD,LePeillet E, Kershaw T, SowinskiP, Meldrum BS and Gray JA: Foetal grafts from hippocampal regio superior alleviate ischaemic-induced behavioural deficits. Behav Brain Res 58: 107-112, 1993.
12. Stein DG, Palatucci C, Kahn D and Labbe R: Temporal factors influence recovery of function after embryonic brain tissue transplants in adult rats with frontal cortex lesions. Behav Neurosci 102: 260-267, 1988.

13. Boockvar JA, Kapitonov D, Kapoor G, Schouten J, Counelis GJ, Bogler O, Snyder EY, McIntosh TK and O'Rourke DM: Constitutive EGFR signaling confers a motile phenotype to neural stem cells. Mol Cell Neurosci 24: 1116-1130, 2003.

14. Watson DJ, Longhi L, Lee EB, Fulp CT, Fujimoto S, Royo NC, Passini MA, Trojanowski JQ, Lee VM, McIntosh TK and Wolfe JH: Genetically modified NT2N human neuronal cells mediate long-term gene expression as CNS grafts in vivo and improve functional cognitive outcome following experimental traumatic brain injury. J Neuropathol Exp Neurol 62: 368-380, 2003.

15. Al Nimer F, Wennersten A, Holmin S, Meijer X, Wahlberg L and Mathiesen T: MHC expression after human neural stem cell transplantation to brain contused rats. Neuroreport 15: $1871-1875,2004$

16. Chiba S, Ikeda R, Kurokawa MS, Yoshikawa H, Takeno M, Nagafuchi H, Tadokoro M, Sekino H, Hashimoto T and Suzuki N: Anatomical and functional recovery by embryonic stem cell-derived neural tissue of a mouse model of brain damage. J Neurol Sci 219: 107-117, 2004.

17. Longhi L, Watson DJ, Saatman KE, Thompson HJ, Zhang C, Fujimoto S, Royo N, Castelbuono D, Raghupathi R, Trojanowski JQ, et al: Ex vivo gene therapy using targeted engraftment of NGF-expressing human NT2N neurons attenuates cognitive deficits following traumatic brain injury in mice. J Neurotrauma 21: 1723-1736, 2004.

18. Bakshi A, Shimizu S, Keck CA, Cho S, LeBold DG, Morales D, Arenas E, Snyder EY, Watson DJ and McIntosh TK: Neural progenitor cells engineered to secrete GDNF show enhanced survival, neuronal differentiation and improve cognitive function following traumatic brain injury. Eur J Neurosci 23: 2119-2134, 2006.

19. Cho YH, Kim HS, Lee KH, Lee YE and Chang JW: The behavioral effect of human mesenchymal stem cell transplantation in cold brain injured rats. Acta Neurochir Suppl 99: 125-132, 2006.

20. Bentz K, Molcanyi M, Riess P, Elbers A, Pohl E, Sachinidis A, Hescheler J, Neugebauer E and Schäfer U: Embryonic stem cells produce neurotrophins in response to cerebral tissue extract: Cell line-dependent differences. J Neurosci Res 85: 1057-1064, 2007.

21. Bjorklund LM, Sánchez-Pernaute R, Chung S, Andersson T, Chen IY, McNaught KS, Brownell AL, Jenkins BG, Wahlestedt C, Kim KS and Isacson O: Embryonic stem cells develop into functional dopaminergic neurons after transplantation in a Parkinson rat model. Proc Natl Acad Sci USA 99: 2344-2349, 2002.

22. Doetsch F, Caillé I, Lim DA, García-Verdugo JM and Alvarez-Buylla A: Subventricular zone astrocytes are neural stem cells in the adult mammalian brain. Cell 97: 703-716, 1999.

23. Lu J, Moochhala S, Moore XL, Ng KC, Tan MH, Lee LK, He B, Wong MC and Ling EA: Adult bone marrow cells differentiate into neural phenotypes and improve functional recovery in rats following traumatic brain injury. Neurosci Lett 398: 12-17, 2006.

24. McFarlin K, Gao X, Liu YB, Dulchavsky DS, Kwon D, Arbab AS, Bansal M, Li Y, Chopp M, Dulchavsky SA and Gautam SC: Bone marrow-derived mesenchymal stromal cells acceleratewound healing in the rat. Wound Repair Regen 14: 471-478, 2006

25. Shamblott MJ, Axelman J, Wang S, Bugg EM, Littlefield JW, Donovan PJ, Blumenthal PD, Huggins GR and Gearhart JD: Derivation of pluripotent stem cells from cultured human primordial germ cells. Proc Natl Acad Sci USA 95, 13726-13731, 1998.

26. Kerr DA, Llado J, Shamblott M, Maragakis N, Irani DN, Dike S, Sappington A, Gearhart J and Rothstein J: Human embryonic germ cell derivatives facillitate motor recovery of rats with diffuse motor neuron injury. J Neurosci 15: 5131-5140, 2001.

27. Fee DB, Sewell DL, Andresen K, Jacques TJ, Piaskowski S, Barger BA, Hart MN and Fabry Z: Traumatic brain injury increases TGF beta RII expression on endothelial cells. Brain Res 1012: 52-59, 2004.

28. Li Y, McIntosh K, Chen J, Zhang C, Gao Q, Borneman J, Raginski K, Mitchell J, Shen L, Zhang J, et al: Allogeneic bone marrow stromal cells promote glial-axonal remodeling without immunologic sensitization after stroke in rats. Exp Neurol 198: 313-325, 2006. 
29. Dihné M,Bernreuther C, Hagel C, Wesche KO and Schachner M: Embryonic stem cell-derived neuronally committed precursor cells with reduced teratoma formation after transplantation into the lesioned adult mouse brain. Stem Cells 24: 1458-1466, 2006.

30. Sun L, Lee J and Fine HA: Neuronally expressed stem cell factor induces neural stem cell migration to areas of brain injury. J Clin Invest 113: 1364-1374, 2004.

31. Philips MF, Muir JK, Saatman KE, Raghupathi R, Lee VM, Trojanowski JQ and McIntosh TK: Survival and integration of transplanted postmitotic human neurons following experimental brain injury in immunocompetent rats. J Neurosurg 90: 116-124, 1999.

32. Philips MF, Mattiasson G, Wieloch T, Björklund A, Johansson BB, Tomasevic G, Martínez-Serrano A, Lenzlinger PM, Sinson G Grady MS and McIntosh TK: Neuroprotective and behavioral efficacy of nerve growth factor-transfected hippocampal progenitor cell transplants after experimental traumatic brain injury. J Neurosurg 94: 765-774, 2001.

33. Lee CS, Tee LY, Dusenbery S, Takata T, Golden JP, Pierchala BA, Gottlieb DI, Johnson EM Jr, Choi DW and Snider BJ: Neurotrophin and GDNF family ligands promote survival and alter excitotoxic vulnerability of neurons derived from murine embryonic stem cells. Exp Neurol 191: 65-76, 2005.

34. Riess P, Zhang C, Saatman KE, Laurer HL, Longhi LG, Raghupathi R, Lenzlinger PM, Lifshitz J, Boockvar J, Neugebauer E, et al: Transplanted neural stem cells survive, differentiate and improve neurological motor function after experimental traumatic brain injury. Neurosurgery 51: 1043-1052; discussion 1052-1054, 2002.

35. Holmin S and Mathiesen T: Intracerebral administration of interleukin-1 beta and induction of inflammation, apoptosis and vasogenic edema. J Neurosurg 92: 108-120, 2000.

36. McIntosh TK, Saatman KE, Raghupathi R, Graham DI, Smith DH, Lee VM and Trojanowski JQ: The Dorothy Russell memorial lecture. The molecular and cellular sequelae of experimental traumatic brain injury: Pathogenetic mechanisms. Neuropathol Appl Neurobiol 24: 251-267, 1998.

37. Ogawa Y, Sawamoto K, Myata T, Miyao S, Watanabe M, Nakamura M, Bregman BS, Koike M, Uchiyama Y, Toyama Y and Okano H: Transplantation of in vitro-expanded fetal neural progenitor cells results in neurogenesis and functional recovery after spinal cord contusion injury in adult rats. $J$ Neurosci Res 69: 925-933, 2002.

38. Xu L, Yan J, Chen D, Welsh AM, Hazel T, Johe K, Hatfield G and Koliatsos VE: Human neural stem cell grafts ameliorate motor neuron disease in sod-1 transgenic rats. Transplantation 82: 865-875, 2006.

39. Wei H, Fiskum G, Rosenthal RE and Perry DC: Global cerebral ischemia and reperfusion alters NMDA receptor binding in canine brain. Mol Chem Neuropathol 30: 25-39, 1997.

40. Miyazaki H, Nagashima K, Okuma Y and Nomura Y: Expression of glial cell line-derived neurotrophic factor induced by transient forebrain ischemia in rats. Brain Res 922: $165-172,2001$

41. Buisson A, Lesne S, Docagne F, Ali C, Nicole O, MacKenzie ET and Vivien D: Transforming growth factor-beta and ischemic brain injury. Cell Mol Neurobiol 23: 539-550, 2003.
42. Sondell M, Lundborg G and Kanje M: Vascular endothelial growth factor has neurotrophic activity and stimulates axonal outgrowth, enhancing cell survival and Schwann cell proliferation in the peripheral nervous system. J Neurosci 19: 5731-5740, 1999.

43. Silverman WF, Krum JM, Mani N and Rosenstein JM: Vascular, glial and neuronal effects of vascular endothelial growth factor in mesencephalic explant cultures. Neuroscience 90: $1529-1541,1999$.

44. Jin KL, Mao XO and Greenberg DA: Vascular endothelial growth factor: Direct neuroprotective effect in in vitro ischemia. Proc Natl Acad Sci USA 97: 10242-10247, 2000.

45. Matsuzaki H, Tamatani M, Yamaguchi A, Namikawa K, Kiyama H, Vitek MP, Mitsuda N and Tohyama M: Vascular endothelial growth factor rescues hippocampal neurons from glutamate-induced toxicity: Signal transduction cascades. FASEB J 15: 1218-1220, 2001.

46. Hayashi T, Abe K and Itoyama Y: Reduction of ischemic damage by application of vascular endothelial growth factor in rat brain after transient ischemia. J Cereb Blood Flow Metab 18: 887-895, 1998.

47. Zhang ZG, Zhang L, Jiang Q, Zhang R, Davies K, Powers C, Bruggen NV and Chopp M: VEGF enhances angiogenesis and promotes blood-brain barrier leakage in the ischemic brain. J Clin Invest 106: 829-838, 2000.

48. Sun Y, Jin K, Xie L, Childs J, Mao XO, Logvinova A and Greenberg DA: VEGF-induced neuroprotection, neurogenesis and angiogenesis after focal cerebral ischemia. J Clin Invest 111: 1843-1851, 2003.

49. Oosthuyse B, Moons L, Storkebaum E, Beck H, Nuyens D, Brusselmans K, Van Dorpe J, Hellings P, Gorselink M and Heymans S, et al: Deletion of the hypoxia-response element in the vascular endothelial growth factor promoter causes motor neuron degeneration. Nat Genet 28: 131-138, 2001.

50. Lambrechts D, Storkebaum E, Morimoto M, Del-Favero J, Desmet F, Marklund SL, Wyns S, Thijs V, Andersson J and van Marion I, et al: VEGF is a modifier of amyotrophic lateral sclerosis in mice and humans and protects motoneurons against ischemic death. Nat Genet 34: 383-394, 2003.

51. Sopher BL, Thomas PS Jr, LaFevre-Bernt MA, Holm IE, Wilke SA, Ware CB, Jin LW, Libby RT, Ellerby LM and La Spada AR: Androgen receptor YAC transgenic mice recapitulate SBMA motor neuronopathy and implicate VEGF164 in the motor neuron degeneration. Neuron 41: 687-699, 2004.

52. Sköld MK, Marti HH, Lindholm T, Lindå H, Hammarberg H, Risling $\mathrm{M}$ and Cullheim S: Induction of HIFlalpha but not HIF2alpha in motoneurons after ventral funiculus axotomy-implication in neuronal survival strategies. Exp Neurol 188: 20-32, 2004.

53. Louissaint A Jr, Rao S, Leventhal C and Goldman SA: Coordinated interaction of neurogenesis and angiogenesis in the adult songbird brain. Neuron 34: 945-960, 2002.

54. Jin K, Zhu Y, Sun Y, Mao XO, Xie L and Greenberg DA: Vascular endothelial growth factor (VEGF) stimulates neurogenesis in vitro and in vivo. Proc Natl Acad Sci USA 99: 11946-11950, 2002.

55. Mahmood A, Lu D, Lu M and Chopp M: Treatment of traumatic brain injury in adult rats with intravenous administration of human bone marrow stromal cells. Neurosurgery 53: 697-702; discussion 702-703, 2003. 